\title{
Conf-9505/2/--2
}

UCRL-JC-118992

PREPRINT

\section{Copper-Diamond Composite Substrates for Electronic Components}

\author{
Howard L. Davidson \\ Sun Microsystems
}

Nicholas J. Colella, John A. Kerns, Daniel Makowiecki

Lawrence Livermore National Laboratory

This paper was prepared for submittal to the

1995 IEEE Electronic Component and Technology Conference

Las Vegas, NV

$5 / 21-24 / 95$

January 25, 1995

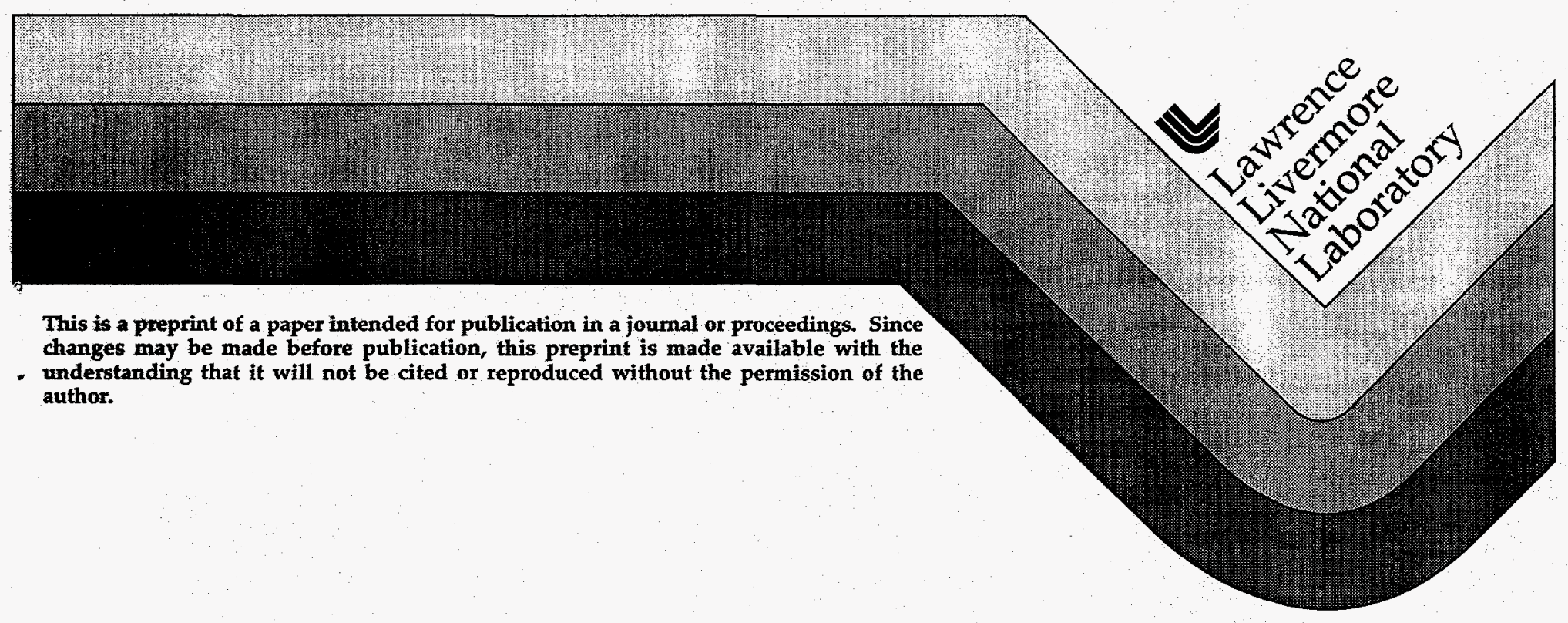




\section{DISCLAMMER}

This document was prepared as an account of work sponsored by an agency of the United States Government. Neither the United States Government nor the University of California nor any of their employees, makes any warranty, express or implied, or assumes any legal liability or responsibility for the accuracy, completeness, or usefulness of any information, apparatus, product, or process disclosed, or represents that its use would not infringe privately owned rights. Reference herein to any specific commercial product, process, or service by trade name, trademark, manufacturer, or otherwise, does not necessarily constitute or imply its endorsement, recommendation, or favoring by the United States Government or the University of California. The views and opinions of authors expressed herein do not necessarily state or reflect those of the United States Government or the University of California, and shall not be used for advertising or product endorsement purposes. 


\section{DISCLAIMER}

Portions of this document may be illegible in electronic image products. Images are produced from the best available original document. 


\author{
Howard L. Davidson \\ Sun Microsystems \\ Mountain View, CA \\ Nicholas J. Colella, John A. Kerns, Daniel Makowiecki \\ Lawrence Livermore National Laboratory \\ Livermore, $\mathbf{C A}$
}

\begin{abstract}
The application of high power density electronic components such as fast microprocessors and power semiconductors is often limited by an inability to maintain the device junctions below their maximum rated operating temperature. The junction temperature rise is determined by the thermal resistance from junction to the ambient thermal environment. Two of the largest contributions to this thermal resistance are the die attach interface and the package base. A decrease in these resistances can allow increased component packing density in MCMs, reduction of heat sink volume in tightly packed systems, enable the use of higher performance circuit components, and improve reliability.
\end{abstract}

The substrate for a multichip module or device package is the primary thermal link between the junctions and the heat sink. Present high power multichip module and single chip package designs use substrate materials such as silicon nitride or copper tungsten that have thermal conductivity in the range of $200 \mathrm{~W} / \mathrm{m} \cdot \mathrm{K}$. We have developed a copper-diamond composite material, named Dymalloy, with a thermal conductivity of $420 \mathrm{~W} / \mathrm{m} \cdot \mathrm{K}$, better than copper, and an adjustable coefficient of thermal expansion, nominally $5.5 \mathrm{ppm} /{ }^{\circ} \mathrm{C}$ at $25^{\circ} \mathrm{C}$, compatible with silicon and gallium arsenide. Because of the matched coefficient of thermal expansion it is possible to use low thermal resistance hard die attach methods.

Dymalloy is a composite material made using micron size Type I diamond powder that has a published thermal conductivity of 600 to $1000 \mathrm{~W} / \mathrm{m} \cdot \mathrm{K}$ in a metal matrix that has a thermal conductivity of 350 $\mathrm{W} / \mathrm{m} \cdot \mathrm{K}$. The region of chemical bonding between the matrix material and diamond is limited to approximately $100 \AA$ to maintain a high effective thermal conductivity for the composite. The material may be fabricated in near net shapes.

Besides having exceptional thermal properties, the mechanical properties of this material also make it an attractive candidate as an electronic component substrate material.

\section{Introduction}

Modem microprocessors have reached a power density of 77 W/cm ${ }^{2}[1]$, have been predicted to rise to $200 \mathrm{~W} / \mathrm{cm}^{2}$ [2], while power semiconductors, such as the $350 \mathrm{~W}$ BUS50 TO-3 power transistor, operate at a maximum power density of $660 \mathrm{~W} / \mathrm{cm}^{2}$ [3]. To ensure correct operation and adequate life it is necessary to limit the junction temperature to less than $200^{\circ} \mathrm{C}$ for discrete power semiconductors, $125^{\circ} \mathrm{C}$ for military logic devices, and as low as $70^{\circ} \mathrm{C}$ for some commercial logic devices. For many high power density devices much of the thermal budget is expended in the die attach thermal resistance and in the package base thermal resistance.

The ideal material for a package base would have infinite thermal conductivity and a coeficient of thermal expansion, (CTE), perfectly matched to the semiconductor material. The need for high thermal conductivity is obvious. The good CTE match is required because the thermally induced shear stress at the die bond is directly proportional to the mismatch in CTE and the length from the center of the die to a corner.

The best thermal conductivity available in a naturally occurring material is about $2200 \mathrm{~W} / \mathrm{m} \cdot \mathrm{K}$ for good quality Type Ila diamond. Pure copper has a thermal conductivity of $393 \mathrm{~W} / \mathrm{m} \cdot \mathrm{K}$. Common package base materials such as copper-tungsten, $\mathrm{AlN}$, and $\mathrm{BeO}$ all have thermal conductivities near $200 \mathrm{~W} / \mathrm{m} \cdot \mathrm{K}$. The new aluminum silicon carbide composites also fall in this range. Copper diamond composite material made with 55 vol\% of good quality Type I diamond has a thermal conductivity of $420 \mathrm{~W} / \mathrm{m} \cdot \mathrm{K}$.

While Type IIa diamond has been successfully employed as a heat spreader for laser diodes and some microwave devices, its CTE of 1.7 $\mathrm{ppm} /{ }^{\circ} \mathrm{C}$, compared to $5.8 \mathrm{ppm} /{ }^{\circ} \mathrm{C}$ for GaAs, limits its use with hard, high thermal conductivity, die attach methods to die generally less than $1 \mathrm{~mm}$ on a side. Copper diamond composite made with $55 \mathrm{vol} \%$ diamond has an almost perfect CTE match to gallium arsenide. Note that increasing the diamond volume fraction allows the CTE to be adjusted to provide a perfect match to silicon. Values for the thermal conductivity and CTE of common semiconductor and substrate materials are shown in Table 1.

Table 1: Properties of Common Semiconductor and Substrate Materials

\begin{tabular}{|l||l|l|}
\cline { 2 - 3 } \multicolumn{1}{c|}{} & $\begin{array}{l}\text { Thermal Conductivity } \\
\mathrm{W} / \mathrm{m} \cdot \mathrm{K}\end{array}$ & $\begin{array}{c}\mathrm{CTE} \\
\mathrm{ppm} /{ }^{\circ} \mathrm{C}\end{array}$ \\
\hline \hline $\mathrm{Si}$ & 150 & 4.2 \\
\hline GaAs & 50 & 5.8 \\
\hline \hline Dymalloy & 420 & 5.5 \\
\hline Copper & 393 & 17 \\
\hline $\mathrm{Cu}-\mathrm{W} 25 / 75$ & 230 & 8.3 \\
\hline BeO & 210 & 6.7 \\
\hline AlN & 180 & 4.5 \\
\hline
\end{tabular}

Modern microprocessor die are often larger than $1.5 \mathrm{~cm}$ on a side. They are most often attached to their packages with a polymer die attach to provide a compliant joint that can absorb the shear stress caused by the difference in CTE between silicon at $4.2 \mathrm{ppm} /{ }^{\circ} \mathrm{C}$ and copper tungsten at $8.3 \mathrm{ppm} /{ }^{\circ} \mathrm{C}$. A good silver-filled epoxy die attach material has a thermal conductivity of $1.9 \mathrm{~W} / \mathrm{m} \cdot \mathrm{K}$. The thermal conductivity of Au-Sn $80 / 20$ die attach alloy is $68 \mathrm{~W} / \mathrm{m} \cdot \mathrm{K}$. For the same power density and thickness the silver-filled epoxy will have 36 times 
the temperature rise of the Au-Sn. Values for the thermal conductivity of some common die attach materials are shown in Table 2.

Table 2: Thermal Conductivity of Common Die Attach Materials

\begin{tabular}{|l|l|}
\cline { 2 - 2 } \multicolumn{1}{c|}{} & $\begin{array}{l}\text { Thermal Conductivity } \\
\text { W/m॰K }\end{array}$ \\
\hline Au-Sn 80/20 & 68 \\
\hline Au-Ge 88/12 & 88 \\
\hline Au-Si 97/3 & 27 \\
\hline Silver Glass & 17 \\
\hline Silver-Filled Epoxy & 1.9 \\
\hline
\end{tabular}

As an example consider a die with a power density of $100 \mathrm{~W} / \mathrm{cm} 2$ attached to a substrate with a $65 \mu$ bond line. Using a silver-filled epoxy die attach will result in a temperature rise of $29^{\circ} \mathrm{C}$. Using a AuSn bond would result in a rise of $0.8^{\circ} \mathrm{C}$. This is smaller than the $4.4^{\circ} \mathrm{C}$ rise through a typical $625 \mu$ thick silicon die under these conditions. For extremely high power density conditions combining thinned die with an activated nitride bond process [4] that can produce a bondline only $2000 \AA$ thick may be appropriate.

Given that the total temperature rise budget from junction to ambient is only $60^{\circ} \mathrm{C}$ in the case of workstations, having a substrate that is CTE matched to the semiconductor provides a major advantage. Using a substrate with more that twice the thermal conductivity of any other CTE matched material provides additional margin.

\section{Fabrication of Dymalloy}

Developing a high thermal conductivity diamond composite substrate material requires an understanding of the primary thermal conduction processes between the diamond and the matrix material. Thermal conduction in diamond and other non-metallic materials is govemed by phonons; whereas electrons are responsible for thermal conduction in metals. Phonon conduction is limited by discontinuities in the material such as inclusions, slip planes, and the interface at the diamond surface boundaries. The diamond size can also affect the thermal conductivity. Electron conduction is also limited by boundary effects between the components of the composite material.

These effects produce two requirements that must be met by the fabrication process. The first is that the diamond powder is readily available and has high thermal conductivity. The ideal diamond powder would be pure crystalline carbon that is free of defects and contaminants. These requirements are approached by Type Ila diamonds, i.e. expensive diamonds used for jewelry, which, for large samples, have a typical thermal conductivity of $2200 \mathrm{~W} / \mathrm{m}-\mathrm{K}$. The more common Type I diamond, commercially available as powder used for manufacturing operations such as grinding and lapping, has a thermal conductivity of 600 to $1000 \mathrm{~W} / \mathrm{m} \cdot \mathrm{K}$ for large diamonds.

Type II diamond powder is not commercially available, and the cost of purchasing and then crushing CVD diamond films for use in the substrate is not economically feasible. Type I diamond powder is readily available at costs between $\$ 0.50$ and $\$ 1.00$ a carat. At these prices the substrate cost is primarily a function of the cost of the materials.

The next consideration in developing this composite material occurs when we estimate the composite's thermal conductivity. We assume that the reported values of diamond thermal conductivity hold for the powder sizes used in making the composite material. There is some experimental evidence in the literature [5] that diamond grain size affects the thermal conductivity of CVD diamond films, and as the grains get larger the thermal conductivity increases until the grains are larger than approximately $20 \mu$.

We have attempted to address diamond size, purity and defects, and interface conditions in developing the present fabrication process for Dymalloy. We have not explored all possible combinations to optimize the material.

A high thermal conductivity diamond composite substrate requires that the diamond be chemically bonded to the matrix material. The metal-carbon bond, or carbide, has relatively poor thermal conductivity. In order to mitigate this effect the total thickness of this bond must be minimized. We have used titanium, tungsten, chrome, and zirconium to form the carbide bond. The majority of Dymalloy composites have been made using tungsten - $26 \%$ rhenium as the interface material. The first step of the fabrication process is coating the diamond powder using a sputter deposition technique. We first coat the diamond with approximately $100 \AA$ of a carbide forming material. We have verified the thickness using TEM analysis.

All of the carbide forming materials oxidize in air and bonding to these oxide surfaces is difficult. We avoid this problem by coating $1000 \AA$ of a brazeable material, such as pure copper, on top of the carbide former in situ. The result of this first fabrication step is coated diamond powder that has $100 \AA$ of a carbide forming material overcoated with $1000 \AA$ of brazeable material.

To ensure uniform coating of the irregular diamond grains the powder is tumbled in the coating system. This is accomplished by placing the powder in a small metal pan that is mechanically vibrated in the vertical direction by a piezo-ceramic transducer.

At this point the coated diamond powder can be packed into a mold and vacuum infiltrated with braze alloy to form the composite material. Although we have made composites using this technique we have found that it is easier to obtain the required shape if the brazeable coating is thicker than $1000 \AA$. We used commercially available copper coated diamond powder to develop the process for packing the powder into molds. Examination of this powder shows that the diamond grains are entrapped within, but not bonded to, the copper, and that the copper coating is several microns thick.

We have made composites with the commercial powder and have found that the powder can be readily formed into the desired shape by filling a mold and mechanically packing the powder. We have experimentally determined the initial filling thickness of the commercial diamond powder, and the pressure necessary to compact the preform, so that the final composite meets thickness and dimensional tolerances.

We increase the copper coating thickness on our coated diamond powder by electroless plating. After this has been done our bonded powder may be directly substituted for the commercial powder used to calibrate the packing process.

The final step is to infiltrate the formed diamond powder with a high thermal conductivity material. We presently use a copper-silver alloy that has a thermal conductivity of $354 \mathrm{~W} / \mathrm{m} \cdot \mathrm{K}$ and a melting point of approximately $800^{\circ} \mathrm{C}$. Other materials such as copper with a thermal conductivity of $393 \mathrm{~W} / \mathrm{m} \bullet \mathrm{K}$ can be used, but the lower melting temperature alloy avoids problems with graphitization of the diamond. 
The infiltration process is done in a vacuum and capillary action allows the metal braze to wick into the preform. Using an amount of braze material just sufficient to thoroughly wet the preform ensures that the composite does not deform upon cooling due to the differences in the CTE between the braze material and the composite. Other manufacturing processes that combine sections of these last two steps can be envisioned but have not tried.

A patent has been applied for on this process.

\section{Material Properties}

- The material properties that have been measured include density, porosity, diamond fraction, specific heat, coefficient of thermal expansion, thermal conductivity, speed of sound, and the mechanical stress strain relation. Some of the properties such as density, specific heat, and the coefficient of thermal expansion can be determined from a rule of mixtures formula using the volume fraction of diamond in the composite and are verified by measurements. These estimates also assume that the composite is fully dense.

The diamond volume fraction is determined by measuring the porosity and density. We determined that the composite was fully dense by using mercury porosimetry technique. Any porosity would have a detrimental affect on the thermal conductivity of the composite. The measured density of $6.4 \mathrm{~g} / \mathrm{cc}$ was then used to determine the diamond volume fraction of $55 \%$.

Both the specific heat and the coefficient of thermal expansion for several test pieces were measured as functions of temperature. The average specific heat for temperatures between 25 and $75^{\circ} \mathrm{C}$ was measured to be $0.316+8.372 \times 10^{-4} \mathrm{~T}(\mathrm{~J} / \mathrm{gK})$. The average CTE between 25 and $200^{\circ} \mathrm{C}$ was $5.48+6.5 \times 10^{-3} \mathrm{~T}(\mathrm{ppm} / \mathrm{C})$.

The thermal conductivity of a composite material is a combination of the thermal conductivities of the constituents. The thermal circuit through the composite is made up of many parallel and series conduction paths. A simple unit cell estimate of the effective thermal conductivity of the composite, assuming the diamond at $1000 \mathrm{~W} / \mathrm{m} \cdot \mathrm{K}$ and the matrix at $400 \mathrm{~W} / \mathrm{m} \cdot \mathrm{K}$ gives $660 \mathrm{~W} / \mathrm{m} \cdot \mathrm{K}$. Bounds on the effective thermal conductivity of the composite can be made using the formula given in [6]. Figure 1 shows the bounds of the effective thermal conductivity for the composite as a function of diamond thermal conductivity.

The speed of sound and the stress - strain relation are difficult to estimate but they were measured. Ultrasound techniques were used to measure the speed of sound at $7000 \mathrm{~m} / \mathrm{s}$ in the copper diamond matrix material. This sound speed is comparable to aluminum, molybdenum, titanium, tungsten carbide, and calcium fluoride. The stress strain relation for Dymalloy shows that the material does have some plastic characteristics. Dymalloy has a linear stress-strain relation for stresses up to $40 \mathrm{kpsi}$ and strains of approximately 0.1 to $0.2 \%$. After this linear region the stress increases and failure occurs between 50 and 60 kpsi at strains of approximately 5.0 to $6.0 \%$. Examination of the fractured surfaces, shown in the magnified portion of Figure 2, shows that brittle fracture occurs in the diamonds and the matrix fails in a ductile manner. Also note that the diamond particles are uniformly distributed in the matrix. The stress-strain relation shows that Dymalloy is not a brittle material and has some plastic characteristics that could prove to be advantageous for manufacturing purposes.

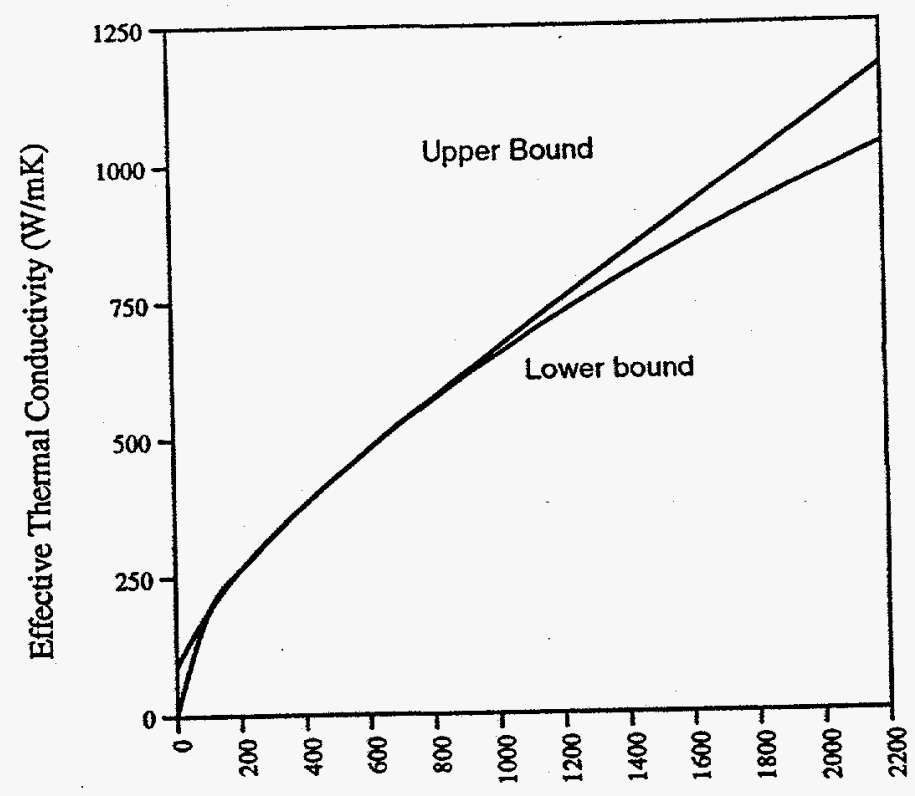

Diamond Thermal Conductivity ( $W / \mathrm{mK})$

Figure 1. Bounds of effective thermal conductivity of the composite. The matrix thermal conductivity is $354 \mathrm{~W} / \mathrm{mK}$ and the volume fraction of diamond is $55 \%$.
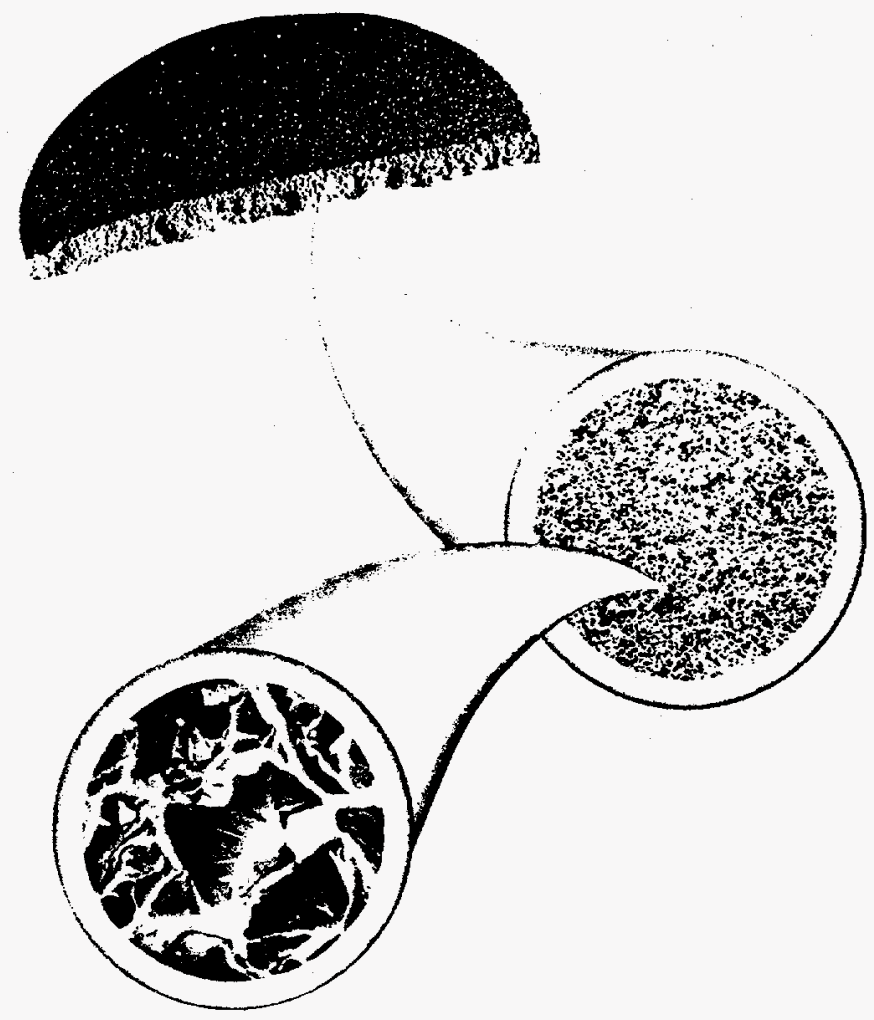

Figure 2. The figure shows two magnified views of the fracture surface of a Dymalloy disc. The lower magnification picture shows the uniform distribution of diamond in the metal matrix. The higher magnification photo at the bottom of the figure reveals high strength cleavage failure in the diamond particles.

Because Dymalloy is fabricated using a powder process it is straightforward to process components to near-net shape. The as fabricated surface has some texture from the embedded diamond particles. If a smoother surface is needed it is possible to plate up the surface and polish it. 
The material is extremely abrasive. Machining with ordinary metal cutting tools is tedious, and requires frequent tool sharpening or replacement. It is possible to machine Dymalloy by etching or electrical discharge machining.

\section{References}

1. W. R. Hamburgen and J. R. Fitch, "Packaging a $150 \mathrm{~W}$ Bipolar ECL Microprocessor," in Proceedings of the 42nd Electronic Components and Technology Conference, IEEE, May 1992, pp. 412-422.

2. G. Sai-Halaz, "Performance Trends in High End Processors," Proc. IEEE, Vol. 83 (1), Jan. 1995, pp 20-36.

3. Direct measurement on delidded BUS50 power transistor. The package was found to contain two $0.50 \times 0.53 \mathrm{~cm}$ die.

4. R. Bower and M. Ismail, "Low Temperature $\mathrm{Si}_{3} \mathrm{~N}_{4}$ Direct Bonding," Appl. Phys. Lett., Vol. 62 (26), 28 June 1993, pp. 3485-3487.

5. J.E. Graebner, S. Jin, G.W. Kammlott, J.A. Herb, and C.F. Gardinier, "Unusually High Thermal Conductivity in Diamond Film," Appl. Phys. Lett. Vol. 60 (13), 30 March 1992, pp. 1576-1578.

6. S. Nomura, and T.W. Chou, "Bounds of Effective Thermal Conductivity of Short Fiber Composites," J. Composite Materials, Vol. 14, April 1980, pp. 120-129.

This work was performed under the auspices of the U.S. Department of Energy by Lawrence Livermore National Laboratory under contract no. W-7405-Eng-48. 